\title{
Target Cell Limited and Immune Control Models of HIV Infection: A Comparison
}

\author{
Rob J. De Boer* $*$ and Alan S. Perelson $\dagger$ \\ * Theoretical Biology, Utrecht University, Padualaan 8, 3584 CH Utrecht, The Netherlands \\ $\uparrow$ Theoretical Division, MS-K710, Los Alamos National Laboratory, Los Alamos, NM 87545, \\ U.S.A.
}

(Received on 27 November 1996, Accepted in revised form on 16 September 1997)

\begin{abstract}
We develop various mathematical models of the clinical latency stage of HIV-1 infection assuming that HIV-1 infection is limited either by the availability of cells that HIV can infect or by a specific anti-HIV cellular immune response. The former models we call "target-cell-limited". Comparing the models by phase plane analysis we find that they all belong to the class of predator-prey models. In the target-cell-limited models the virus is a predator feeding upon target cell prey, while in the immune-control models the virus is a prey that is controlled by an immune response predator. Because both classes of models are of predator-prey type they behave similarly in most circumstances. We find that both types of model can account for the generic picture of disease progression in which the CD4 $\mathrm{T}$ cell count slowly decreases and the viral load slowly increases. Additionally, we find that both types of models can adequately describe the clinically observed changes in the plasma HIV-1 RNA loads in response to retroviral therapies.
\end{abstract}

(C) 1998 Academic Press Limited

\section{Introduction}

A typical HIV-1 infection has a long clinical latency phase (Coffin, 1995). Following an initial viremia, the viral load in peripheral blood declines rapidly and establishes a quasi-steady state level. The length of the clinical latency phase correlates negatively with the quasi-steady state level that is attained shortly after the initial viremia (Mellors et al., 1996). During disease progression there is a slow increase in the viral load, and a slow decrease in the $\mathrm{CD}^{+} \mathrm{T}$ cell count in peripheral blood. Because of the slowness of disease progression, it had been thought that the processes of HIV-1 replication and the destruction of infected $\mathrm{CD}^{+}$cells would also have a slow time-scale. This viewpoint has recently been contradicted by mathematical analysis of data obtained in patients

\# Author to whom correspondence should be addressed. E-mail: rdb@alive.biol.ruu.nl treated with anti-viral drugs inhibiting either HIV-1 protease (Ho et al., 1995; Perelson et al., 1996) and/or HIV-1 reverse-transcriptase (RT) (Wei et al., 1995; Perelson et al., 1997). Following such a therapeutic perturbation of the quasi-steady state, the HIV-1 RNA load and the $\mathrm{CD}^{+} \mathrm{T}$ cell count in the peripheral blood change drastically on a time-scale of weeks. It was estimated that in patients with CD4 counts below 500, the average HIV-1 generation time is 2-3 days (Ho et al., 1995; Wei et al., 1995), leading to $\sim 140$ generations per year (Perelson et al., 1996), and that the average total HIV-1 production is about $10^{10}$ virions per day (Perelson et al., 1996). Clinical latency therefore appears to be a quasi-steady state in which fast HIV-1 replication and clearance remain in almost perfect balance. According to this view, disease progression involves a slow change of parameters that gradually moves the quasi-steady state to higher viral loads and consequently lower $\mathrm{CD} 4^{+} \mathrm{T}$ cell counts. 
The crucial question arising from this novel view is the nature of the processes setting the long-term balance between viral replication and clearance (Coffin, 1995). One obvious control process is the anti-viral immune response. HIV-1 infection elicits both humoral and cellular immune responses (Fauci, 1993; Weiss, 1993). CD ${ }^{+}$T lymphocytes, which suppress and/or kill virus infected cells, are thought to be the dominant defense mechanism, and it has been postulated that long term survival is associated with a good cellular immune response (Klein et al., 1995; Rinaldo et al., 1995; Shearer \& Clerici, 1996; Nowak \& Bangham, 1996; Levy et al., 1996; Wolinsky et al., 1996; Goulder et al., 1997; Borrow et al., 1997). Another significant control factor is the availability of "target" cells, i.e. cells that HIV is able to infect (Coffin, 1995; Phillips, 1996; De Boer \& Boucher, 1996). The primary target of HIV-1 infection is an activated $\mathrm{CD}^{+} \mathrm{T}$ cell (Fauci, 1993; Weiss, 1993).

A variety of clinical data sets suggest that virus replication is limited by the availability of target cells. Suppressing the immune system with either cyclosporine (Andrieu et al., 1988; Schwarz et al., 1993; Weber \& Galpin, 1995) or prednisolone (Andrieu et al., 1995; Corey, 1995) can have beneficial effects because it decreases the $\mathrm{CD}^{+}{ }^{+} \mathrm{T}$ cell count and sometimes (Weber \& Galpin, 1995) decreases the viral load. Stimulating the immune system with IL-2 tends to increase the viral load (Kovacs et al., 1995). Immunization of HIV-1 infected patients with either influenza vaccine (Staprans et al., 1995; O'Brien et al., 1995), hepatitis B vaccine (Cheeseman et al., 1996), pneumococcal vaccine (Brichacek et al., 1996), or tetanus toxoid (Stanley et al., 1996), which should activate $T$ cells, tends to increase the viral load. A similar increase in HIV is seen during infection with pathogenic organisms (Goletti et al., 1996). Because the number of activated $\mathrm{CD} 4{ }^{+} \mathrm{T}$ cells, i.e. target cells, decreases with immune suppression and increases with immune stimulation, these results suggest that the infection may be "target-cell-limited" during such post-treatment transients. Finally, monotherapy with the anti-retroviral drug didanosine unexpectedly gives a long-term suppression of HIV-1 when it is combined with the immunosuppressive drug hydroxyurea (Vila et al., 1996; Lori et al., 1997). Precisely this long-term effect was previously predicted by studies of target-cell-limited models (De Boer \& Boucher, 1996).

In this paper we perform a comparative study of target-cell-limited and immune-controlled models of HIV infection. To enable an objective comparison between models we set the unknown parameters such that the models all have a similar clinical latency steady state. This is the equivalence approach advocated by Irvine \& Savageau (1995a,b). Our main conclusion is that both target-cell limited and immune control models have similar behavior, and can account for the dynamics observed after drug perturbation experiments.

\section{Biological Variables and Parameters}

The models that we develop involve various cells types: non-infected quiescent $\mathrm{T}$ cells, $Q$, (non-infected) activated or cycling $\mathrm{CD}^{+}$cells, which we consider to be target cells $T$, productively infected $\mathrm{T}$ cells, $I$, cytotoxic effector T cells, $E$, and HIV-1 virus particles, $V$. (Parameter and variable names follow the "Arden Accord", http://binf.biol.ruu.nl/ rdb/arden.html.) Recent studies on the dynamics of HIV-1 turnover and the rate of $\mathrm{CD}^{+}{ }^{+} \mathrm{T}$ cell recovery following the administration of antiretroviral drugs provide estimates for some of the parameters of the models. In HIV-infected patients the division rate of $\mathrm{CD}^{+} \mathrm{T}$ cells decreases approximately linearly with the CD4 $\mathrm{T}$ cell count, suggesting that the growth rate is density dependent and is governed by a logistic-like growth function (Sachsenberg et al., submitted). The CD4 cell count in an uninfected individual is approximately $1000 \mathrm{CD}^{+} \mathrm{T}$ cells per $\mu 1$. Estimating the maximum growth rate is difficult, but an upper estimate is provided by the recovery rate of about 0.1 per day during treatment (Ho et al., 1995; Wei et al., 1995). The average lifetime of a productivity infected $\mathrm{T}$ cell is estimated to be between 1 and 2 days (Ho et al., 1995; Wei et al., 1995; Perelson et al., 1996, 1997), and the average lifetime of virus particles is estimated to be maximally $8 \mathrm{hr}$ (Perelson et al., 1996).

The clinical status of a patient is typically assessed by measuring CD4 $\mathrm{T}$ cells counts and viral loads in the blood. The typical patient that we consider has a $\mathrm{CD}^{+} \mathrm{T}$ cell count of say 200 cells per $\mu 1$, and a viral load of approximately $10^{5}$ virions per $\mathrm{ml}$ of plasma. In our models virus particles, $V$, are produced by productively infected cells, $I$, at rate $p$ per cell, and are cleared at a per capita rate $c$, i.e.

$$
\frac{\mathrm{d} V}{\mathrm{~d} t}=p I-c V,
$$

where the clearance rate constant $c$ may involve binding of particles to cells and clearance by antibodies. Because the dynamics of the viral particles are much faster than the dynamics of cells, [Perelson et al. (1996) estimated $c \geqslant 3 \mathrm{day}^{-1}$, we make a quasi-steady state assumption for eqn (1), i.e.

$$
\bar{V}=(p / c) I,
$$


where the overbar denotes a steady-state quantity. The production rate $p$ has been estimated to be approximately $p=100$ (Haase et al., 1996; Cavert et al., 1997) virions per cell per day. Given the viral clearance rate $c=3$ day $^{-1}$, our typical viral load of $\bar{V}=$ 100 virions $\mu 1^{-1}$ yields an estimate of $\bar{I}=3$ cells $\mu 1^{-1}$.

With these parameters, a patient having a typical CD4 count of 200 cells $\mu 1^{-1}$, would have $1.5 \%$ of $\mathrm{CD}^{+} \mathrm{T}$ cells productively infected. We will show below that this fraction is too low to account by itself for significant $\mathrm{CD}^{+}{ }^{+} \mathrm{T}$ cell depletion. Thus, in our models we allow for depletion mechanisms other than productive infection. Additional depletion effects, such as apoptosis, have been used before (Frost \& Michie, 1996) and have been introduced to account for the sustained effect of therapy on reducing viral load (Bonhoeffer et al., 1997). If in the blood and in the lymphoid tissue the same percentage of $\mathrm{CD}^{+} \mathrm{T}$ cells are productively infected, and if $2 \%$ of the $\mathrm{CD}^{+}$ $\mathrm{T}$ cells are in the blood, then $1.5 \%$ of CD4 T cell being productively infected implies a total body burden of $3 \mu 1^{-1} \times 5 \times 10^{6} \mu 1 \times 50=7.5 \times 10^{8}$, which is high when it is compared with recent studies measuring numbers of productively infected $\mathrm{CD}^{+} \mathrm{T}$ cells in the lymphoid tissue. Measured total body loads were $4 \times 10^{7}$ (Haase et al., 1996) and $3 \times 10^{7}$ (Chun et al., 1997) productively infected $\mathrm{CD}^{+} \mathrm{T}$ cells. Given experimental detection limits the former study estimates a total number of $2 \times 10^{8}$ productively infected CD4 ${ }^{+} \mathrm{T}$ cells (Haase et al., 1996). A similar estimate can be arrived at from data measuring that the frequency of mononuclear cells with greater than 20 copies of HIV-1 RNA was $3.1 \times 10^{5}$ per gram of lymphoid tissue (Cavert et al., 1997). Assuming that these cells are productively infected, and that $1 \%$ of the body mass is lymphoid tissue, one again obtains $2 \times 10^{8}$ productively infected cells. Since total CD4 ${ }^{+}$ $\mathrm{T}$ cell levels in these patients is of order magnitude $10^{11}$ cells, one arrives at the very low frequencies of $10^{-3}$ (Haase et al., 1996) to $10^{-4}$ (Chun et al., 1997) productively infected $\mathrm{CD}^{+}{ }^{+} \mathrm{T}$ cells. We will show below that one can obtain indeed obtain similar low frequencies in our models if we were to allow for a larger burst size $p$ and significant $\mathrm{CD}^{+}$depletion by mechanisms other than productive infection. Understanding the mechanisms of $\mathrm{CD}^{+}{ }^{+} \mathrm{T}$ cell depletion with so few productively infected $\mathrm{CD}^{+} \mathrm{T}$ cells remains a major unresolved issue in HIV infection.

\section{Target Cell Limitation}

LOGISTIC MODEL

Recent data measuring the number of dividing $\mathrm{CD}^{+} \mathrm{T}$ cells in $\mathrm{HIV}$-infected patients with different CD4 cell counts suggest a logistic-like growth function (Sachsenberg et al., submitted). Thus, we model the population dynamics of target cells, $T$, and productively infected cells, $I$, as

$$
\begin{gathered}
\frac{\mathrm{d} T}{\mathrm{~d} t}=\alpha_{T} T\left(1-T_{t o t} / T_{\max }\right)-(\beta+\gamma) T V, \\
\text { and } \frac{\mathrm{d} I}{\mathrm{~d} t}=\beta T V-\delta_{I} I,
\end{gathered}
$$

where $V$ is described by eqn (1) or (2). Here $\beta$ is a true infection rate (cells per particle per day) and $\gamma$ combines all other virus induced depletion of the $\mathrm{CD}^{+} \mathrm{T}$ cells. This may vary from apoptosis (Meyaard et al., 1992) to destruction of lymphoid tissue (Pantaleo et al., 1993; Pantaleo, 1997). The rate of increase $\alpha_{T}=0.1 \mathrm{day}^{-1}$ is the maximum rate of $\mathrm{T}$ cell renewal, $T_{\max }=1000$ cells $\mu 1^{-1}$ is the non-infected steady state CD4 count, and $\delta_{I}=0.5$ day $^{-1}$ is the turnover rate of productively infected $\mathrm{T}$ cells. The CD4 count, i.e. the total number of $\mathrm{T}$ cells, $T_{\text {tot }}=T+I$. The steady state of this model is at

$$
\begin{gathered}
\bar{T}=\frac{c \delta_{I}}{p \beta}, \quad \bar{I}=\frac{c \alpha_{T}\left(p \beta T_{\max }-c \delta_{I}\right)}{p \beta\left(\alpha_{T} c+p(\beta+\gamma) T_{\max }\right)}, \\
\text { and } \quad \bar{V}=\frac{p}{c} \bar{I} .
\end{gathered}
$$

We set parameters such that this steady state corresponds to a CD4 $\mathrm{T}$ cell count of approximately 200 cells $\mu 1^{-1}$ and a viral load of $10^{5}$ virions $\mathrm{ml}^{-1}$. Importantly, without the additional depletion term, $\gamma T V$, this model cannot account for such a steady state CD4 $\mathrm{T}$ cell count with so few productively infected $\mathrm{T}$ cells. First, we consider a patient with a steady state CD4 count of $\bar{T}_{t o t} \simeq \bar{T}=200$ and calculate the number of productively infected cells $\bar{I}$ for $\gamma=0$. Requiring $\bar{T}=200$, we solve eqn (4a) for $p \beta$, which is the only unknown parameter combination, to find $p \beta=(0.5 \times 3) / 200=7.5 \times 10^{-3}$. Having estimated $p \beta$, we know all parameters in the steady-state expression for the infected cells [eqn (4b)], and hence find that $\bar{I} \simeq 30$ cells $\mu \mathrm{l}^{-1}$. This corresponds to more than $10 \%$ productively infected cells. Second, consider a patient with a steady state viral load of $10^{5}$ virions $\mathrm{ml}^{-1}$, i.e. $\bar{V}=100 \mu \mathrm{l}^{-1}$, and $\bar{I}=3 \mu 1^{-1}$, for whom we compute the steady state CD4 count. Requiring $\bar{I}=3$, we solve the quadratic eqn (4b) for $\beta$, to find that $\beta=1.5 \times 10^{-5}$ or $\beta=9.8 \times 10^{-4}$. Substituting into eqn (4a), with $p=100$, yields uninfected CD4 ${ }^{+} \mathrm{T}$ cell counts of 982 and 15 cells $\mu 1^{-1}$, respectively. Only in the latter case do we find significant $\mathrm{T}$ cell depletion but again we have more than $10 \%$ productively infected cells. Thus, we see that when the fraction of productively infected $\mathrm{CD}^{+}{ }^{+} \mathrm{T}$ cells is low, other mechanisms beside 
productive infection are required to account for significant $\mathrm{CD}^{+} \mathrm{T}$ cell depletion. Similar results pertain to the activated $\mathrm{T}$ cell model (see below).

The depletion parameter $\gamma$ allows us to scale the number of productively infected cells to arbitrarily low levels. Note from eqn (4) that increasing $\gamma$ lowers $\bar{I}$ but leaves $\bar{T}$ unchanged. Lowering $\bar{I}$ will lower $\bar{V}$, but this can be compensated for by increasing the virion production rate $p$. Having empirical estimates for the production rate, we set $p=100$ and compute from eqn (4c) that, for $\bar{V}=100$ virions $\mu 1^{-1}, \bar{I}=3$ cells $\mu 1^{-1}$. If $\bar{T}_{\text {tot }}=200$ then $\bar{T}=197$, and by eqn (4a) we obtain that $\beta=7.6 \times 10^{-5}$ virion $^{-1}$ day $^{-1}$. Next we solve eqn (4b) with $\bar{I}=3$ and find that $\gamma=7.2 \times 10^{-4}$ virion $^{-1} \mathrm{day}^{-1}$. Thus, to account for a steady state with a $\mathrm{CD}^{+} \mathrm{T}$ cell level of 200 and a viral load of $\bar{V}=100$ virions $\mu 1$, the additional depletion rate $\gamma$ has to be almost 10 -fold larger than the infection rate $\beta$. According to this logistic model, the direct impact of productive infections on $\mathrm{CD}^{+} \mathrm{T}$ cell depletion should be marginal.

\section{ACTIVATED T CELL MODEL}

Activated $\mathrm{T}$ cells make better targets for HIV infection than quiescent cells (Bukrinsky et al., 1991). Thus, we propose a second target-cell-limited model in which we distinguish quiescent and activated $\mathrm{T}$ cells (McLean \& Kirkwood, 1990; McLean \& Nowak, 1992b; Essunger \& Perelson, 1994). In this particular model (Stilianakis et al., 1997), we assume that quiescent $\mathrm{T}$ cells are activated at rate $\alpha_{Q}$, die at rate $\delta_{Q}$, and appear by the proliferation of activated $\mathrm{T}$ cells at a maximum rate $r$. Activated CD4 cells, $T$, appear by activation of quiescent cells, they revert to the quiescent state at rate $r$, and they are infected by virus at a rate $\beta$. Thus,

$$
\begin{gathered}
\frac{\mathrm{d} Q}{\mathrm{~d} t}=\frac{2 r T}{1+T_{\text {tot }} / T_{\max }}-\left(\alpha_{Q}+\delta_{Q}\right) Q, \\
\text { and } \frac{\mathrm{d} T}{\mathrm{~d} t}=\alpha_{Q} Q-r T-(\beta+\gamma) T V,
\end{gathered}
$$

where the $2 /\left(1+T_{\text {tot }} / T_{\max }\right)$ term defines a density dependent regulation of the proliferation rate. When $T_{t o t}=T_{\max }$ proliferation stops, and activated $\mathrm{T}$ cells simply revert to the quiescent state. For the infected $\mathrm{T}$ cells we copy eqn (3b), i.e.

$$
\frac{\mathrm{d} I}{\mathrm{~d} t}=\beta T V-\delta_{I} I
$$

and $V$ is still given by eqn (1).
The total number of $\mathrm{T}$ cells, i.e. the CD4 count, in this model is $T_{t o t}=Q+T+I$. The clinical latency steady state is at

$$
\begin{gathered}
\bar{T}=\frac{c \delta_{I}}{p \beta}, \quad \bar{I}=\frac{\alpha_{Q} \bar{Q} \beta}{\delta_{I}(\beta+\gamma)}-\frac{c r}{p(\beta+\gamma)}, \\
\text { and } \quad \bar{V}=\frac{p}{c} \bar{I} .
\end{gathered}
$$

The value of $\bar{Q}$ can easily be computed; it is too complicated to warrant printing here.

For the lifespan of quiescent human $\mathrm{CD}^{+} \mathrm{T}$ cells we employ our three year estimate (De Boer \& Noest, submitted) based upon telomere data in normal individuals (Weng et al., 1995), i.e. we set $\delta_{Q}=0.001$ day $^{-1}$. By setting $r=1$ day $^{-1}$ we assume that activated $\mathrm{T}$ cells revert quite rapidly to the quiescent state. In the Appendix we derive that the maximum growth rate of the $\mathrm{CD} 4$ population is determined by the activation rate $\alpha_{Q}$ and that the CD4 cell count should remain below $T_{\max }$. Using the maximum growth rate estimated above, we set $\alpha_{Q}=0.1 \mathrm{day}^{-1}$. Further, setting $\bar{T}_{\max }=1200$ we obtain a normal CD4 cell count of approximately $1000 \mathrm{CD}^{+} \mathrm{T}$ cells per $\mu \mathrm{l}$. We numerically fit $\beta$ and $\gamma$ for the required steady state, i.e. we set $\beta=1.35 \times 10^{-3}$ and $\gamma=5.6 \times 10^{-3}$ to have a steady state, $T_{\text {tot }} \simeq 200$ cells $\mu 1^{-1}, \bar{Q} \simeq 188$ cells $\mu 1^{-1}$, $\bar{T} \simeq 11$ cells $\mu 1^{-1}, \bar{I} \simeq 3$ cells $\mu 1^{-1}$, and $\bar{V} \simeq 100$ particles $\mu 1^{-1}$. All other parameters remain the same as those in the logistic model. Note that $\beta \simeq \gamma / 4$, i.e. $\sim 25 \%$ of the depletion is accounted for by productive infections. Further, because only a small fraction of all $\mathrm{CD}^{+} \mathrm{T}$ cells are now target cells, the infection rate $\beta$ is about 100 -fold higher than it is in the logistic model.

\section{PHASE PLANE RESULTS}

Comparing the two target-cell-limited models by phase plane analysis we point out their similarity and their relationship to predator-prey models. We reduce both models to two ODEs by making a quasi-steady state assumption for virus [eqn (2)], and a second quasi-steady state assumption for the target cell population, $T$, in the activated $\mathrm{T}$ cell model. Plotting the "prey" population $T$ (or $Q$ ) on the horizontal axis and the "predator" population $I$ on the vertical axis, we obtain two very similar phase plane pictures (see Fig. 1). In the logistic model the location of the vertical predator nullcline determines the CD4 cell count of the latency steady state. We indeed have set the CD4 count to 200 by tuning the infection rate $\beta$. For these parameter values the steady state is a stable spiral point. The nullclines of the activated $\mathrm{T}$ cell 
model [Fig. 1(b)] resemble those of the logistic model, but the prey nullcline (heavy line) is slightly curved and the predator nullcline (light line) is slanted. The steady state remains a stable spiral point, but tends to be more stable than that of Fig. 1(a).

\section{DISEASE PROGRESSION}

For a typical patient, during the asymptomatic, clinical latency phase the CD4 cell count slowly decreases and the viral load slowly increases. The onset of AIDS is defined as reaching a CD4 count of 200 cells $\mu 1^{-1}$ or below. An aim of theoretical modeling is to find a disease progression parameter that decreases the CD4 count and increases the viral load. This is an interesting problem because one would expect the viral load to decrease with decreasing CD4 counts if the virus is target-cell-limited. If this were true, it would contradict the data, and would be an argument against a target cell limited model.

We can incorporate disease progression into the model by assuming that the virus increases its infection rate $\beta$. This assumption has been the focus of a model developed by Schenzle (1994) and is in agreement with data suggesting that the virus quasispecies becomes more virulent during progression (Tersmette et al., 1989; Schellekens et al., 1992; Connor \& Ho, 1994), but is at odds with other data suggesting that the virulence remains similar (Wolinsky et al., 1996). In the clinical latency steady

(a)

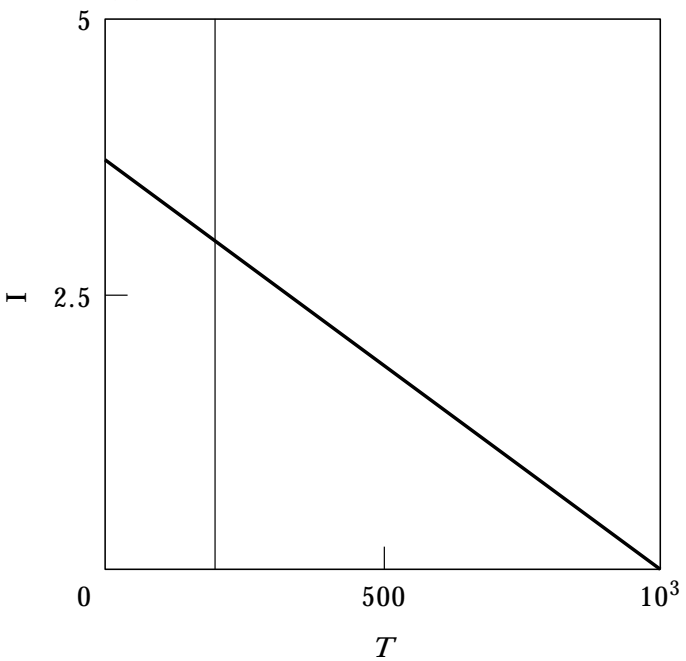

state of the logistic model, eqn (4), the CD4 count, $\bar{T}$, is an inverse function of the infection rate $\beta$. The viral load is a complicated function of $\beta$ however. When $\beta$ is small, increasing $\beta$ increases the viral load; when $\beta$ is large it is the other way around [Fig. 2(a)].

In Fig. 2(a) we plot the steady state viral load and CD4 count as a function of $\beta$ in the logistic model. Disease progression is interpreted as an increase of $\beta$ in time. Observe that CD4 count, $T$ (light line), is inversely related to $\beta$, and that the viral load (dark line) first increases and then decreases. This decrease of the viral load is in disagreement with the data, but is natural in simple host-parasite models. For the current parameters the equilibrium is stable only for $\beta<1.4 \times 10^{-4}$; the model behavior is oscillatory otherwise (not shown).

Other parameters that might change during disease progression are $T_{\max }$, the maximum $\mathrm{T}$ cell count, the additional depletion $\gamma$, and $\alpha_{T}$ or $\alpha_{O}$, the $\mathrm{T}$ cell self-renewal rates. A biological argument for decreasing $T_{\max }$ would be that during HIV-1 infection lymphoid tissues is destroyed (Pantaleo et al., 1993; Pantaleo, 1997), which could lower the maximum number of $\mathrm{T}$ cells that can be maintained. An argument for choosing $\alpha_{T}$ or $\alpha_{Q}$ as a progression parameter is that HIV-1 infection involves hyperactivation of the immune system (Fauci, 1993). However $\gamma, \alpha_{T}$ and $T_{\max }$ are all absent from the steady-state equation for uninfected $\mathrm{T}$ cell of the logistic model [eqn 4(a)]. Thus, changing any of them fails to

(b)

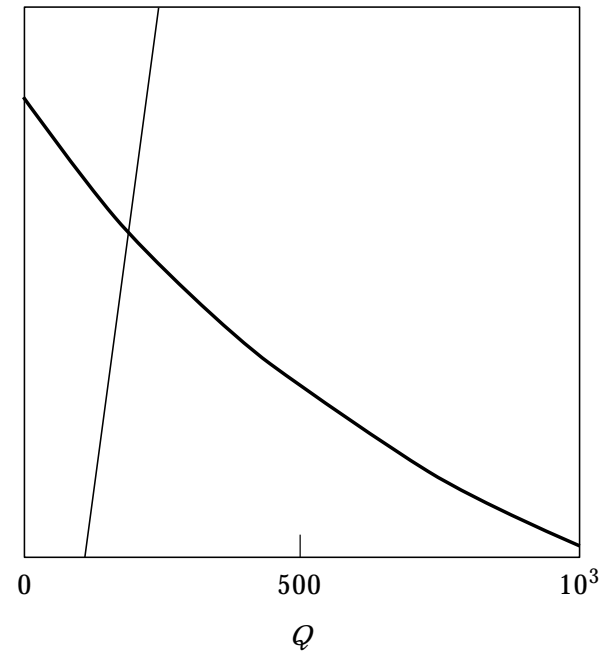

FIG. 1. Nullclines of the target-cell-limited models. Making quasi-steady state assumptions for the virus particles, and for target cells in the activated T cell model, both models become two-dimensional, and can be analyzed in a phase-plane. The heavy line is the nullcline of the prey species $\left(T\right.$ or $Q$ ) and the light line is the nullcline of the predator, $I$. Panel (a) depicts the logistic model for $\beta=7.5 \times 10^{-5}$, $\gamma=7.2 \times 10^{-4}, \alpha_{T}=0.1 \mathrm{day}^{-1}$, and $T_{\max }=1000$ cells. Panel (b) depicts the activated $\mathrm{T}$ cell model for $\alpha_{Q}=0.1, r=1, \delta_{Q}=0.001$, $\beta=0.00135, \gamma=0.0056$, and $T_{\max }=1200$. Invariant parameters: $p=100 \mathrm{day}^{-1}, \delta_{I}=0.5 \mathrm{day}^{-1}$, and $c=3 \mathrm{day}^{-1}$. 
(a)

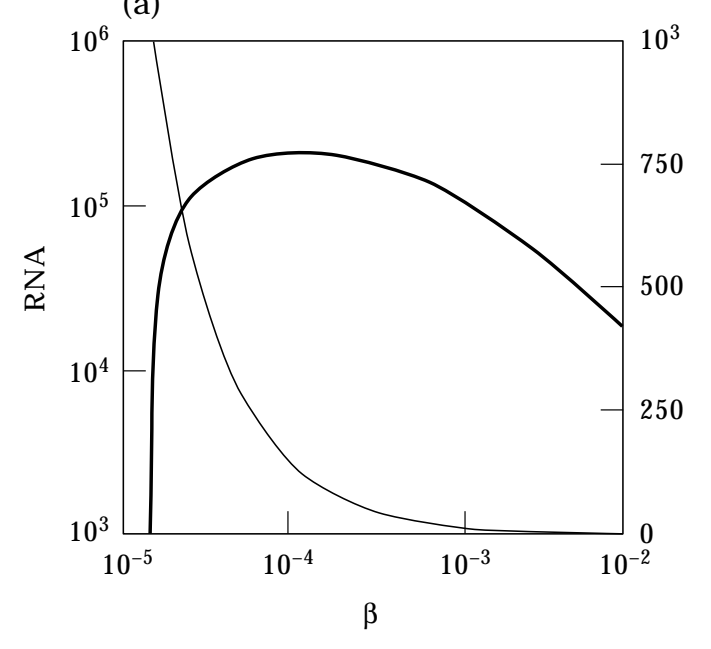

(b)

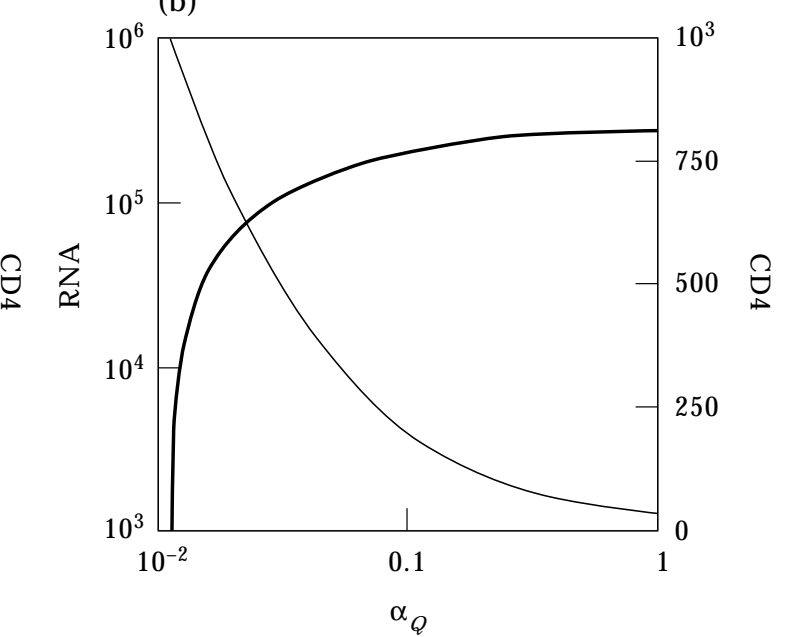

FIG. 2. Disease progression studied by continuing the clinical latency steady state as a function of a "progression" parameter. The light line is the CD4 count per $\mu 1$ on a linear scale. For the logistic model (a) we pick the infection rate $\beta$ as the disease progression parameter. (It should be noted that the equilibrium is involved in a Hopf bifurcation around $\beta=0.00014$, not shown.) For the activated T cell model we obtain realistic disease progression by picking the T cell activation rate $\alpha_{Q}$ as a progression parameter. The viral load is measured by the conventional HIV-1 RNA load per ml, i.e. $r n a=2000 \mathrm{~V}$.

decrease the CD4 cell count. This occurs because in the logistic model the CD4 count is set by parameters of the virus only [see eqn 4(a)], and because the additional depletion parameter $\gamma$ merely scales the number of productively infected cells.

Interestingly, changing the $\mathrm{T}$ cell activation rate, $\alpha_{Q}$, seems to be the best parameter for modeling progression in the activated $\mathrm{T}$ cell model. Increasing $\alpha_{Q}$ decreases the number of quiescent $\mathrm{T}$ cells and hence causes the CD4 $\mathrm{T}$ cell count to go down and the viral load to go up [Fig. 2(b)]. Moreover, recent data (Chun et al., 1997; Sachsenberg et al., submitted) suggest that as $\mathrm{T}$ cell counts fall a higher fraction of CD4 cells are activated. This demonstrates that target-cell-limited models can account for the observed clinical pattern of decreasing CD4 counts and increasing viral loads during disease progression. The equilibrium is stable over the full range of $\alpha_{Q}$ values depicted in Fig. 2(b). Modeling disease progression by increasing virus infectivity, i.e. $\beta$, in the activated $\mathrm{T}$ cell model yields results that are similar to those of the logistic model [cf. Fig. 2(a)].

\section{INTERPRETATION}

The activated $\mathrm{T}$ cell model is superior to the logistic model for two reasons. First, its better stability properties allow for higher infection rates $\beta$. Second, the activated $\mathrm{T}$ cell model can account for the typical picture of disease progression by increasing $\mathrm{T}$ cell activation [Fig. 2(b)]. The logistic model only has a small parameter range of low infection rates $\beta$ where as $\beta$ increases viral loads go up and CD4 counts go down [Fig. 2(a)]. Thus, disease progression is more difficult to explain with the logistic model than with the activated T cell model. Phase plane analysis shows that activated $\mathrm{T}$ cell model is a predator-prey model with a slanted predator nullcline, whereas the logistic model has a vertical nullcline. This tends to make the clinical latency steady state more stable in the activated $\mathrm{T}$ cell model.

\section{Immune-control}

\section{CYTOTOXIC T CELL (CTL) MODEL}

An alternative to target cell limitation of HIV replication is immune control. We define an immune-control model as one in which the high turnover rate of infected cells $\delta_{I}=0.5 \mathrm{day}^{-1}$ is entirely due to their removal by $\mathrm{CD} 8^{+}$CTLs. This is extreme but it allows us to clearly distinguish immune control models from target cell limited models. The turnover rates of CTLs can be estimated from data on other viral infections. Following the successful clearance of an LCMV infection, the CTL effector levels drop $95 \%$ in about 3 weeks (Ahmed \& Gray, 1996). Thus, we calculate that the turnover of the CTLs should maximally be on the order of $\delta_{E} \simeq 0.2$ day $^{-1}$ [i.e. $\ln (0.05) / 21=-0.14]$.

In order to distinguish between target cell limitation and immune control, we need to assume in 
an immune-control model that virus replication is not limited by the target cell density. We thus assume that

$$
\frac{\mathrm{d} I}{\mathrm{~d} t}=\beta V-k I E
$$

Note, $\beta$ now has units of $\mathrm{day}^{-1}$ and that in essence a constant value of $T$ has been incorporated into $\beta$. We assume that $V$ is still given by eqn (1).

It is possible to develop a class of models that are intermediate between target cell limitation and immune control by assuming that the rate of target cell infection is a saturating function of the target cell density, $T$, i.e.

$$
\frac{\mathrm{d} I}{\mathrm{~d} t}=\beta V \frac{T}{\theta+T}-k I E
$$

For $\theta \gg T$, this reduces to the target cell limited model, whereas for $\theta \ll T$ one obtains the immune control model.

To make the model of eqn (9) "equivalent" to the target cell limited models we require that at the latency steady state $\delta_{I}=k \bar{E}=0.5 \mathrm{day}^{-1}$, so that productively infected cells are lost at the observed rate of $0.5 \mathrm{day}^{-1}$. Solving eqn (9) and using eqn (2) we obtain $\bar{E}=p \beta /(c k)$. Since $c=3 \mathrm{day}^{-1}$, this allows us to compute the product of the infection rate and the production rate as $p \beta=c k \bar{E}=1.5 \mathrm{day}^{-1}$. Choosing our earlier estimate of a production rate of $p=100$ virions per productively infected cell per day we obtain $\beta=0.015$ day $^{-1}$.

Considering such a simple "pure" immune-control model however forces us to develop a relatively sophisticated model for the CTLs. Combining eqn (9) with the simplest possible CTL model, i.e.

$$
\frac{\mathrm{d} E}{\mathrm{~d} t}=\alpha_{E} E I-\delta_{E} E,
$$

yields the well-known structurally non-robust LotkaVolterra predator-prey model with perpendicular nullclines [see Fig. 3(a)]. Nowak \& Bangham (1996) report for a similar class of models that the steady-state viral load is determined only by immune-control parameters. Indeed, solving eqn (11), we obtain $\bar{I}=\delta_{E} / \alpha_{E}$. Thus, the number of productively infected cells is independent of parameters describing viral replication. Since we require $I=3$ at steady state, and $\delta_{E}=0.2$ day $^{-1}$, we find that we must choose $\alpha_{E}=0.067$ day $^{-1}$.

One can make this model more realistic by using an activation function that saturates, i.e.

$$
\frac{\mathrm{d} E}{\mathrm{~d} t}=\frac{\alpha_{E} E I}{1+\epsilon_{I} I}-\delta_{E} E
$$

Now, CTL activation/proliferation has a maximal rate of $\alpha_{E} / \epsilon_{I}$. Solving eqn (12) for the equilibrium value of $V$, we obtain $\bar{I}=\delta_{E} /\left(\alpha_{E}-\delta_{E} \epsilon_{I}\right)$. This still yields a non-robust perpendicular nullcline [see Fig. 3(b)]. Assuming a maximum CTL proliferation rate of about one doubling per day, i.e. assuming $\alpha_{E} / \epsilon_{I}=1$ day $^{-1}$, we obtain the required $\bar{I}=3$ by setting $\alpha_{E}=\epsilon_{I}=0.08333$.

We can obtain a structurally robust immune-control model by employing the model of De Boer \& Perelson (1995) that allows for competition between (a)

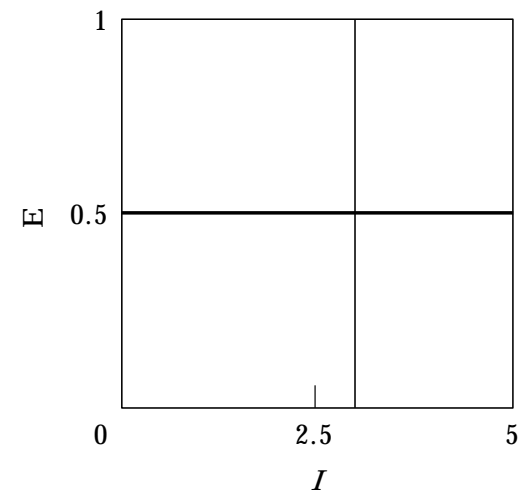

(b)

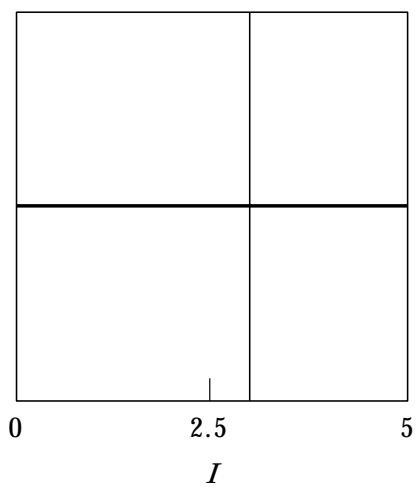

(c)

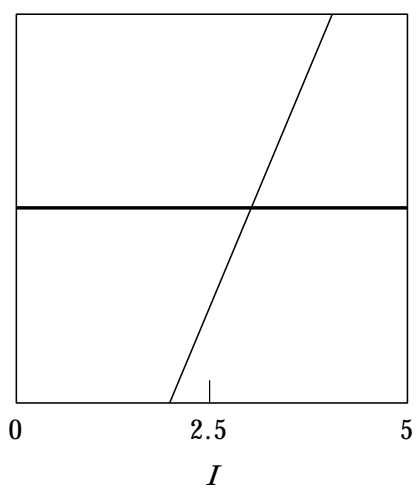

FIG. 3. Nullclines of the three immune-control models. The heavy line is the nullcline of the prey species (i.e. $I$ ) and the light line is the nullcline of the predator, $E$. Parameters: (a) $\alpha_{E}=0.002, \epsilon_{I}=\epsilon_{E}=0$; (b) $\alpha_{E}=\epsilon_{I}=0.08333, \epsilon_{E}=0$; (b) $\alpha_{E}=\epsilon_{I}=0.125, \epsilon_{E}=1$; Invariant parameters: $\delta_{E}=0.2$ day $^{-1}, p=100$ day $^{-1}, \delta_{I}=0.5$ day $^{-1}$, and $c=3$ day $^{-1}$. 
CTLs when interacting with infected cells. In this model,

$$
\frac{\mathrm{d} E}{\mathrm{~d} t}=\frac{\alpha_{E} E I}{1+\epsilon_{I} I+\epsilon_{E} E}-\delta_{E} E .
$$

The maximum per capita proliferation rate is still $\alpha_{E} / \epsilon_{I}=1$, and $\epsilon_{E}$ defines the intensity of the competition. The steady state of this model, found by solving eqns (1), (9), and (13), is

$$
\bar{E}=\frac{p \beta}{k c}, \quad \bar{I}=\frac{\delta_{E}\left(k c+\epsilon_{E} p \beta\right)}{k c\left(\alpha_{E}-\delta_{E} \epsilon_{I}\right)}, \quad \text { and } \quad \bar{V}=\frac{p}{c} \bar{I} .
$$

Note that $\bar{I}$ now depends on the viral parameters $p$ and $\beta$. In this model the $I$-nullcline is slanted, making the model structurally stable, and the steady state is stable [see Fig. 3(c)]. Setting $\epsilon_{E}=1, k=1$, and requiring $\alpha_{E} / \epsilon_{I}=1$ and $\bar{I}=3$, we find $\alpha_{E}=\epsilon_{I}=0.125$.

There are alternative ways to make the immunecontrol model structurally robust. For example, one could allow some target cell limitation, i.e. use eqn (10) instead of (9), or one could include a source of naive cells into the CTL equation. With a fully activated and proliferating CTL population such a source term should make a relatively small contribution to the population size. We prefer to use the model with competition, eqn (13), because a small source term, or a small effect of target-cell-limitation, would only make the model marginally stable. Further, using eqn (13) the steady-state value of $V$ depends on immune system parameters, which is a desirable feature in an immune control model.

\section{DISEASE PROGRESSION}

In immune-control models a natural method for modeling disease progressing is to decrease the activation/proliferation rate $\alpha_{E}$ of the CTLs. Such a decline could be due to the senescence of CTLs, as recently observed via telomere shortening (Effros et al., 1996; Wolthers et al., 1996), and/or to decreased $\mathrm{T}$ cell help due to progressive $\mathrm{CD}^{+}{ }^{+} \mathrm{T}$ cell loss. Focusing on the structurally stable immune-control model, we see from eqn (14) that decreasing $\alpha_{E}$ increases $\bar{I}$ and hence the steady-state viral load without affecting the steady-state level of the immune response, $\bar{E}$. Since the steady state in the pure immune-control models is independent of the CD4 cell count, one can easily account for the typical picture of disease progression by independently assuming that the CD4 cell count decreases with increasing viral load.

Alternatively one may model disease progression by allowing the virus to evolve immune-escape variants increasing the diversity of the quasi-species
(Nowak \& May, 1991; Nowak et al., 1991; Nowak \& Bangham, 1996; De Boer \& Boerlijst, 1994; Wolinsky et al., 1996). Since this requires high-dimensional models, this form of disease progression is not considered any further here.

\section{INTERPRETATION}

Models of HIV infection that are purely immunecontrolled also have the form of predator-prey models. The proliferation/activation function of the CTLs that we use in eqn (14) is known in ecology as the Beddington (1975) "functional response". Modeling disease progression in immune-control models can be done by reducing the immune responsiveness parameter $\alpha_{E}$.

\section{Anti-viral Treatment}

The activated $\mathrm{T}$ cell model and the CTL model have similar phase planes and can both account for the typical scheme of disease progression. We now compare their behavior when HIV infection is treated by either a protease inhibitor or an RT inhibitor. An $\mathrm{RT}$ inhibitor is expected to reduce the infection rate $\beta$, whereas a protease inhibitor reduces or eliminates the production of infectious virions. A previous model of protease inhibitor action (Perelson et al., 1996) distinguished between infectious and non-infectious virions. One can simplify matter in two ways. First, if the number of infectious virions decreases this in turn will reduce the infection rate. Thus, one can approximate the action of protease inhibitors as a decrease in $\beta$. Second, one can assume that in the presence of a protease inhibitor the total virion production rate $p$ decreases.

First consider treatment with an RT-inhibitor that brings about a two-fold reduction in the infection rate $\beta$. In Fig. 4 the light lines depict the pre-treatment situation (i.e. the same nullclines as those in Fig. 1), and the heavy lines are the nullclines for this two-fold RT-inhibitor treatment. Recall that $\bar{I}$ and $\bar{V}$ are proportional, so that $\bar{I}$ is a measure of the viral load. We observe that if $\beta$ is reduced a new steady state is attained, which in the activated $\mathrm{T}$ cell model is located at an almost two-fold higher CD4 count and a somewhat lower infected cell level and hence lower virus load [Fig. 4(a)]. In the CTL model this treatment brings about an two-fold reduction of the immune response and a somewhat lower viral load [Fig. 4(b)]. Thus, even in the absence of drug resistance, an RT-inhibitor treatment hardly influences the equilibrium viral load. Instead it largely increases CD4 count in the target-cell-limited model (Stilianakis et al., 1997; Bonhoeffer et al., 1997), and decreases the 
(a)

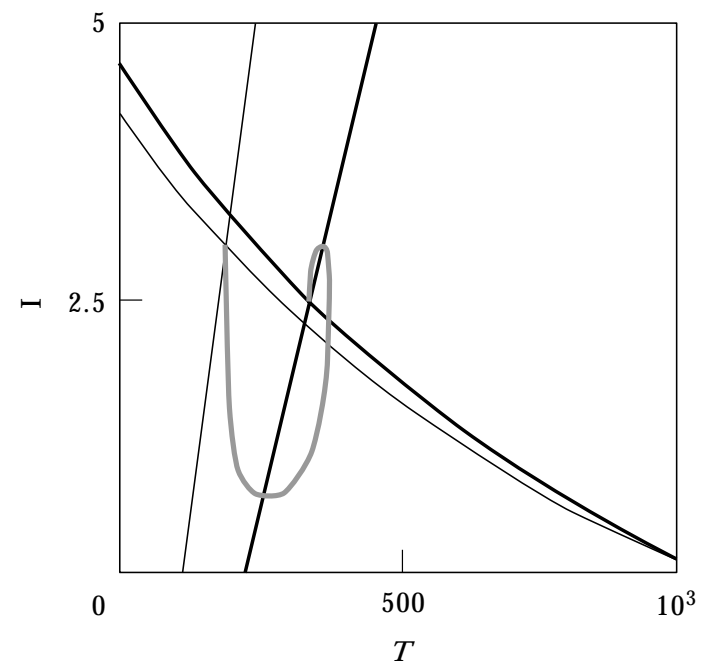

(b)

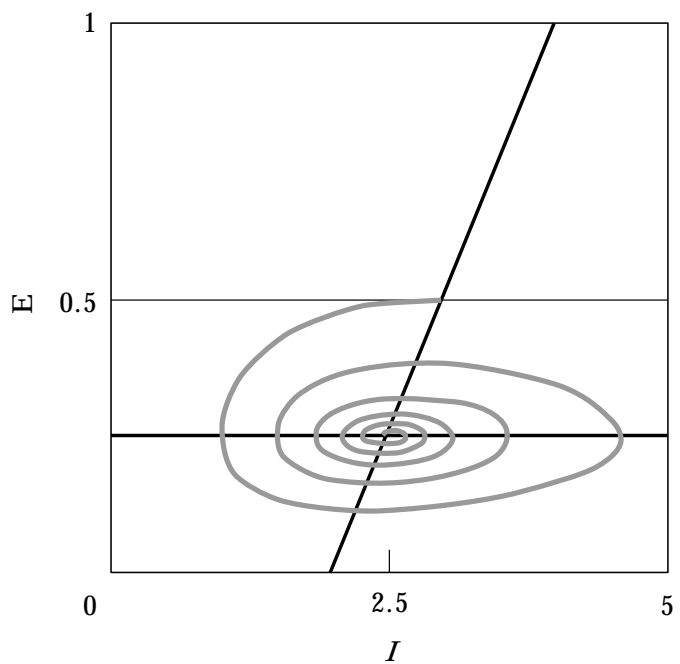

FIG. 4. A two-fold effective RT-inhibitor treatment. The light lines depict the nullclines of Fig. $1 \mathrm{~b}$ and $3 \mathrm{c}$, respectively. The effect of reducing $\beta$ two-fold in (a) the activated T cell model and in (b) the immune control model of Fig. 3(c) is depicted by the heavy nullclines. The gray lines depict trajectories corresponding to this anti-viral treatment. One observes that the viral load (as measured by the $I$ variable) initially declines, and ultimately attains a steady-state level that is similar to the pre-treatment level. Parameters as in Figs 1 and 3.

immune response in the CTL model. Treatment with a drug that reduces $p$ has very similar effects (see below).

The heavy gray lines in Fig. 4 depict the trajectories corresponding to giving this two-fold RT-inhibitor treatment to a patient in the clinical latency steady state. Transiently the virus load is significantly reduced by such a treatment, but the virus rebounds and attains the new steady state. Recent clinical data have confirmed that the wild-type virus load declines and rebounds before drug resistance evolves (De Jong et al., 1996). Previous theoretical studies on target-cell-limited models have predicted the decrease and rebound of wild-type virus due to the typical oscillatory nature of predator-prey interactions (McLean \& Nowak, 1992a; Frost \& McLean, 1994; De Jong et al., 1996; Stilianakis et al., 1997). Because the CTL model is also a predator-prey model, the same type of viral decline and rebound can be seen in immune-control models. Thus, the rebound in viral load can not be used as evidence in favor of a target cell limited model.

The trajectories in Fig. 4 do not allow one to compare the time courses of viral rebound between the two models and the clinical data. For the target cell limited models it has been well established that for current parameter values one obtains a good correspondence between the predicted and observed time course of viral load changes (De Jong et al., 1996; De Boer \& Boucher, 1996; Stilianakis et al., 1997). A similar good correspondence is also possible in the immune-control models (not shown). With drugs such as AZT used as monotherapy the viral load typically rebounds in about a month (De Jong et al., 1996). A good fit to such data therefore requires a fairly high turnover of the immune effector cells $E$ (not shown). Because cytotoxic effector cells are known to be short-lived (Ahmed \& Gray, 1996), immune-control can in principle account for a realistic time course of the viral load. In our models we have not allowed for immune memory however. In patients one would expect the decline of the immune response during anti-viral therapy to be slower due to immune memory effects. In this case, target-cell-limitation is expected to be the dominant control process during the first weeks of treatment.

\section{Therapy and Drug Resistance}

Monotherapy with protease or RT-inhibitors generally results in the eventual development of drug resistance (Larder et al., 1989; Boucher et al., 1992; Wei et al., 1995; Lineberger et al., 1995). In the presence of antiretroviral treatment, the drug-sensitive wild type virus is ultimately outcompeted by drug-resistant variants having a higher infection rate $\beta$, or viral production rates $p$. Thus, in terms of our models, antiretroviral treatment and the development of drug resistance correspond to changes in either $\beta$ or $p$. Plotting the equilibrium viral load as a function of either $\beta$ or $p$ (Fig. 5), allows us to examine the effects of antiretroviral treatment in the presence of drug resistance. For example in Fig. 5(b), starting at a virion production rate of $p=100$ particles per cell 
per day, a drug treatment that decreases $p$ corresponds to moving leftwards. Note that a drug effect that reduces $p$ up to a four-fold reduces the viral load only marginally. Further reduction of $p$ causes the virus to "suddenly" be eradicated. The subsequent development of drug resistance corresponds to moving rightwards, i.e. to increasing $p$. This will increase the viral load again. The light lines in Fig. 5 depict the response of the CD4 count, or the immune response, to changing $\beta$ or $p$ by treatment and resistance development.

In both the activated $\mathrm{T}$ cell and the immune-control model either form of antiretroviral treatment, and of resistance, hardly affects the equilibrium viral load until a (transcritical) bifurcation point is reached. In the target-cell-limited model this is the critical treatment level that reduces $p$ or $\beta$ below the value needed to sustain the virus. In the immune-control model the bifurcation point is where the bifurcation parameter equals zero. Reducing parameters to zero is not realistic however. Note that the immune response, $E$, declines linearly with $\beta$ or $p$. Hence at some point the effect of the immune response is so small that some form of target cell limitation should take over as a control mechanism.

\section{INTERPRETATION}

In both target-cell-limited and in immune-control situations an antiretroviral treatment with limited effects (e.g. due to drug resistance) has a negligible effect on the viral load. The effect of the treatment is largely reflected in the levels of either the target cells or the immune response. A treatment with a sufficiently strong impact eradicates the drug-sensitive virus when the virus is target-cell-limited, but first eradicates the immune response when the virus is (a)

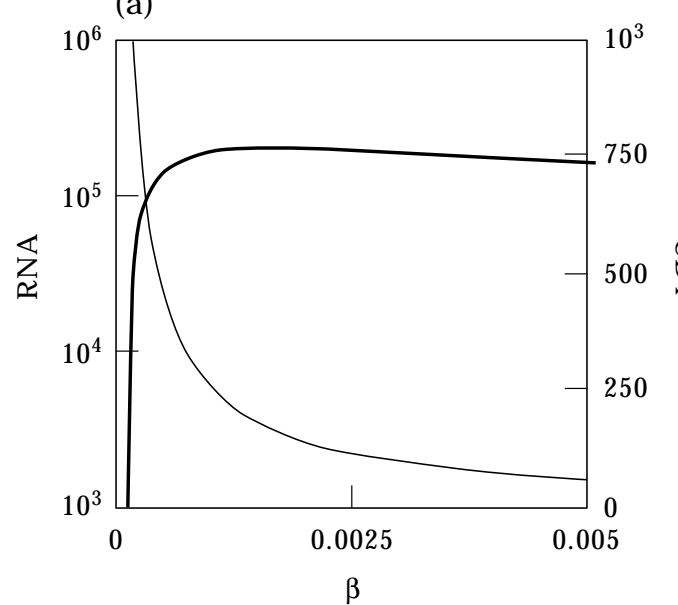

(c)

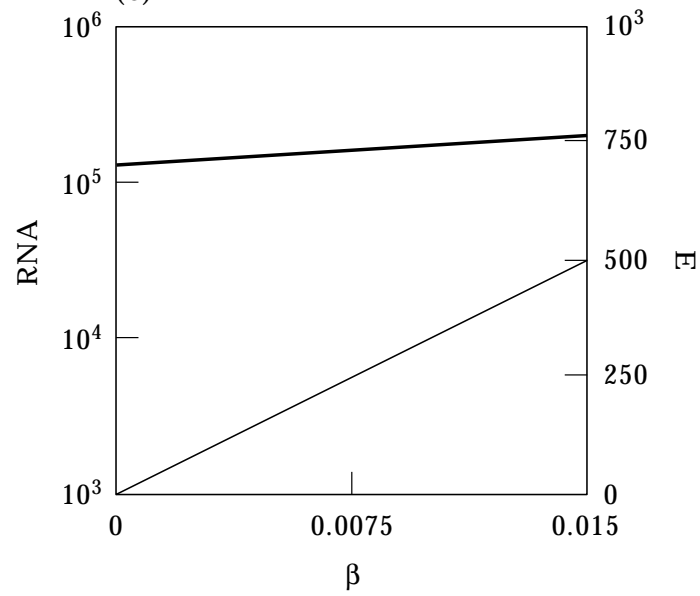

(b)

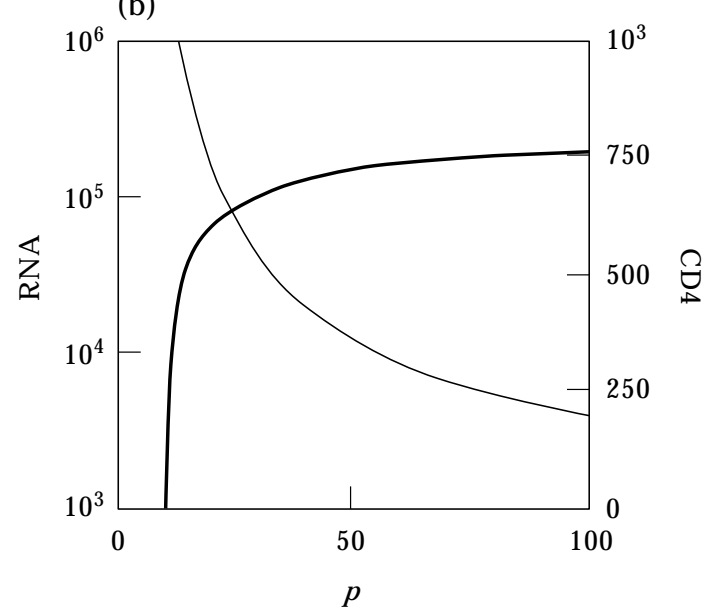

(d)

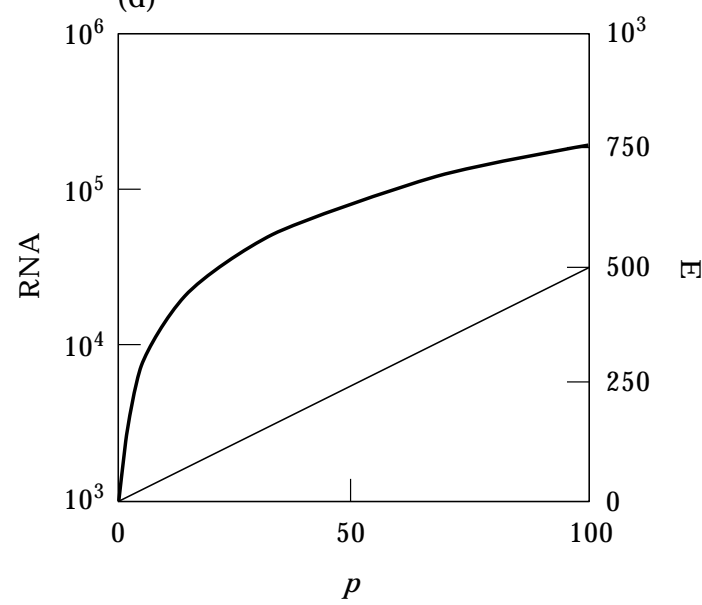

FIG. 5. Protease and RT-inhibitor treatment. (a,b) the equilibrium viral load (dark line) and CD4 T cell count (light line) as a function of the infection rate, $\beta$, and the virion production rate, $p$, in the activated $\mathrm{T}$ cell model. (c,d) the equilibrium viral load (dark line) and the effector cell level, $E$ (light line). One observes that the effects of drug therapy and resistance are largely reflected in the CD4 T cell count $(\mathrm{a}, \mathrm{b})$ or in the immune response level $(\mathrm{c}, \mathrm{d})$; up to the bifurcation points the viral load hardly changes. Parameters as in Figs 1 and 3. 
immune-controlled. This makes sense from an ecological point of view because the predator should go extinct before the prey.

\section{HIV Can be Viewed as Either a Predator or a Prey}

Obviously the target-cell-limited and the immunecontrol models can be combined. In such models, where the target cells form a prey species, the virus is a predator, and the immune response is a superpredator. Such a "food-chain" model can provide further insights in the control processes regulating the viral load (Nowak \& Bangham, 1996). The simplest food-chain model employs eqn (11) for $E$ the "super-predator" population (cf. Nowak \& Bangham, 1996). By the solution of eqn (11), $\bar{I}=\delta_{E} / \alpha_{E}$, one would conclude that the steady-state viral load is determined by the immune-control parameters $\delta_{E}$ and $\alpha_{E}$ only (Nowak \& Bangham, 1996). Thus, in a food-chain model immune control would seem to dominate over target cell limitation.

Generally, this need not be true however. First, there is a non-robustness in this argument because adding yet another level to the food chain, i.e. a population regulating the CTL numbers, would make the virus target-cell-limited again. To see this, we add a regulator population $R$, which changes eqn (11) into the system

$$
\begin{gathered}
\frac{\mathrm{d} E}{\mathrm{~d} t}=\alpha_{E} E I-\delta_{E} E-k_{R} E R, \\
\frac{\mathrm{d} R}{\mathrm{~d} t}=\alpha_{R} R E-\delta_{R} R,
\end{gathered}
$$

where $k_{R}$ determines the magnitude of a possibly very small down-regulatory effect of $R$ on $E$. Solving eqn (15) we obtain $\bar{E}=\delta_{R} / \alpha_{R}$ and $\bar{R}=\left(\alpha_{E} I-\delta_{E}\right) / k_{R}$. Observe that the effector level is independent of the magnitude, $k_{R}$, of the down-regulatory effect. Furthermore, since eqn (15) is required for determining $\bar{E}$ and $\bar{R}$, the equilibrium viral load $\bar{V}$ and $\bar{I}$ have to be solved from the remaining equations of the model [e.g. eqn (2) and (10)]. Since these do not depend on the immune-control parameters $\alpha_{E}$ and $\delta_{E}$ the viral load is target-cell-limited again. In theoretical ecology this is a well known result. For instance, in Lotka-Volterra type models, the effects of an enrichment of a food-chain system differ when the food chain has an even or odd length (Ginzburg \& Akçakaya, 1992). This problem could well be an artifact of the over-simplified interaction terms that are used in these ecological models [and in the immune control model of eqn (11)]. A solution to this problem is to allow for a direct form of competition
(Beddington, 1975; Ginzburg \& Akçakaya, 1992; Abrams, 1994; Huisman \& De Boer, 1997), as we have in eqn (13) and in De Boer \& Perelson (1994, 1995).

Second, when the virus load is so high that the immune response can be considered to be at a maximal level, e.g. by saturation and competition [cf. eqn (13)], the HIV infection also becomes target cell limited. Indeed, allowing for competition amongst the CTLs [cf. eqn (14)] makes the viral load dependent on many more parameters [cf. eqn (15)] than those of the immune response. Third, the time-scale with which the CTL response declines following a perturbation of the clinical latency steady state by therapeutic intervention may be much slower that the time-scale with which the target cell levels rise. This makes HIV transiently target cell limited.

\section{Discussion}

The available data do not allow us to distinguish between our simple target cell limited and immune control models. One approach is to concentrate on the more complicated "food-chain" or "combined" models that incorporate target cell limitation, virus, and immune control (Nowak \& Bangham, 1996). We have seen above however that such models suffer from a non-robustness because adding another level to the food-chain, i.e. any population down-regulating the immune response, has a major impact on the results. Additionally, realistic models should allow for saturation [cf. eqn (10) and/or competition, cf. eqn (13)] effects. It is well known in theoretical ecology that in food-chain models such effects easily lead to humped-shaped nullclines, Hopf-bifurcations, high amplitude oscillatory behavior and/or chaos (Hastings \& Powell, 1991). Thus, the behavior of such a model soon becomes too complex for addressing the simple questions of interest in HIV infection.

An argument in favor of immune control models is the strong dependence of the viral load on the immune responsiveness $\alpha_{E}$ (Nowak \& Bangham, 1996). Individual variations in the immune responsiveness therefore provide a good explanation for the enormous variation in the viral loads of different individuals (Mellors et al., 1996). Individuals might indeed differ in their immune responsiveness because of MHC differences. A more speculative argument slightly in favor of immune control is that CD4 depletion occurs with a low fraction of productively infected cells. In the target-cell-limited models we had to rely on depletion mechanisms beside productive infection to account for significant CD4 depletion. 
From the viewpoint of immune control one would need to argue that most target cells infected by the virus are eliminated by the immune response before they can be detected as productively infected cells [and before they produce virus (Klenerman et al., 1996). To the extend that this is true, this would account for a greater turnover of target cells than that estimated by the low numbers of productively infected cells (Haase et al., 1996; Chun et al., 1997; Cavert et al., 1997).

There is also convincing evidence however that target cell availability plays a role. Increasing target cell levels by IL-2 treatment (Kovacs et al., 1995) or by vaccination (Staprans et al., 1995; O'Brien et al., 1995; Cheeseman et al., 1996; Stanley et al., 1996; Brichacek et al., 1996) tends to increase the virus load. Because such therapeutic interventions are perturbations of the clinical latency steady state, the reported effects on the viral load could just reflect a transient impact of increased target-cell-availability. Thus, these data do not rule out the possibility that the equilibrium viral load is largely immune controlled. Similar ambiguities are to be expected in other experiments manipulating target cell numbers. More convincing results are therefore expected from immunosuppression experiments during clinical latency: immune-control models would unequivocally predict a rise of the viral load, whereas target-cell-limited models predict a drop. The fact that immunosuppression sometimes has beneficial effects (Andrieu et al., 1988, 1995; Corey, 1995; Schwarz et al., 1993; Weber \& Galpin, 1995; Vila et al., 1996; Lori et al., 1997) is a strong argument in favor of target cell limitation.

Our comparative modelling approach shows that both target-cell-limited and immune-control models are similar predator-prey models, and can hence account for most of the available data. The best discrimination between the two classes of models is provided by immunosuppression experiments where immune-control models unequivocally predict a rise in the viral load, whereas target-cell-limited models predict a drop (De Boer \& Boucher, 1996). It is disappointing therefore that recent clinical monotherapy trials with the immunosuppressive drug hydroxyurea fail to find any significant effect on the viral load (Giacca et al., 1996; Simonelli et al., 1996), suggesting that immune-control and target-cell-availability could be about equally important. This would call for the development of novel "food-chain" models in which the steady-state level of the predator HIV is more or less equally determined by its limiting resource, the target cells, and it top-predator, the immune response.
Portions of this work were performed under the auspices of the U.S. Department of Energy. This work was supported by the National Institutes of Health (RR06555, AI40387) and the Santa Fe Institute Theoretical Immunology Program through a grant from the Joseph P. and Jeanne M. Sullivan Foundation. Our scientific collaboration was further supported by a grant from NATO (GRC960019).

\section{REFERENCES}

Abrams, P. A. (1994). The fallacies of "ratio-dependent" predation. Ecology 75, 1842-1850.

Ahmed, R. \& GRAY, D. (1996). Immunological memory and protective immunity: understanding their relation. Science $\mathbf{2 7 2}$, 54-60.

Andrieu, J. M., Even, P., Venet, A., Tourani, J. M., Stern, M., LOWENSTEIN, W., et al. (1988). Effects of cyclosporin on T-cell subsets in human immunodeficiency virus disease. Clin. Immunol. Immunopathol. 47, 181-198.

Andrieu, J. M., Lu, W. \& LeVy, R. (1995). Sustained increases in CD4 cell counts in asymptomatic human immunodeficiency virus type 1-seropositive patients treated with prednisolone for 1 year. J. Infect. Dis. 171, 523-530.

BedDington, J. R. (1975). Mutual interference between parasites or predators and its effect on searching efficiency. J. Anim. Ecol. 51, 597-624.

Bonhoeffer, S., Coffin, J. M. \& Nowak, M. A. (1997). Human immunodeficiency virus drug therapy and virus load. J. Virol. 71, 3275-3278.

Borrow, P., Lewicki, H., Wei, X., Horwitz, M. S., Peffer, N., Meyers, H., et al. (1997). Antiviral pressure exerted by HIV-1-specific cytotoxic T lymphocytes (CTLs) during primary infection demonstrated by rapid selection of CTL escape virus. Nat. Med. 3, 205-211.

Boucher, C. A., O'Sullivan, E., Mulder, J. W., Ramautarsing, C., Kellam, P., Darby, G., et al. (1992). Ordered appearance of zidovudine resistance mutations during treatment of 18 human immunodeficiency virus-positive subjects. J. Infect. Dis. 165, $105-110$.

Brichacek, B., Swindells, S., Janoff, E. N., Pirruccello, S. \& Stevenson, M. (1996). Increased plasma human immunodeficiency virus type 1 burden following antigenic challenge with pneumococcal vaccine. J. Infect. Dis. 174, 1191-1199.

Bukrinsky, M. I., Stanwick, T. L., Dempsey, M. P. \& Stevenson, M. (1991). Quiescent T lymphocytes as an inducible virus reservoir in HIV-1 infection. Science 254, 423-427.

Cavert, W., Notermans, D. W., Staskus, K., Wietgrefe, S. W., Zupancic, M., Gebhard, K., et al. (1997). Kinetics of response in lymphoid tissues to antiretroviral therapy of HIV-1 infection. Science 276, 960-964.

Cheeseman, S. H., Davaro, R. E. \& Ellison, 3Rd, R. T. (1996). Hepatitis B vaccination and plasma HIV-1 RNA. N. Engl. J. Med. 334, 1272.

Chun, T. W., Carruth, L., Finzi, D., Shen, X., DiGiuseppe, J. A., TAYLOR, H., et al. (1997). Quantification of latent tissue reservoirs and total body viral load in HIV-1 infection. Nature 387, 183-188.

Coffin, J. M. (1995). HIV population dynamics in vivo: implications for genetic variation, pathogenesis, and therapy. Science 267, 483-489.

Connor, R. I. \& Ho, D. D. (1994). Human immunodeficiency virus type 1 variants with increased replicative capacity develop during the asymptomatic stage before disease progression. J. Virol. $\mathbf{6 8}$, 4400-4408.

CoRey, L. (1995). Reducing T cell activation as a therapy for human immunodeficiency virus infection. J. Infect. Dis. 171, $521-522$.

De Boer, R. J. \& Boerlijst, M. C. (1994). Diversity and virulence thresholds in AIDS. Proc. Natl. Acad. Sci. U.S.A. 91, 544-548. 
De Boer, R. J. \& Boucher, C. A. (1996). Anti-CD4 therapy for AIDS suggested by mathematical models. Proc. R. Soc. Lond., B, Biol. Sci. 263, 899-905.

De Boer, R. J. \& Perelson, A. S. (1994). T cell repertoires and competitive exclusion. J. theor. Biol. 169, 375-390.

De Boer, R. J. \& Perelson, A. S. (1995). Towards a general function describing $\mathrm{T}$ cell proliferation. J. theor. Biol. 175, $567-576$.

De Jong, M. D., Veenstra, J., Stilianakis, N. I., Schuurman, R., Lange, J. M., De Boer, R. J. \& Boucher, C. A. (1996). Host-parasite dynamics and outgrowth of virus containing a single K70R amino acid change in reverse transcriptase are responsible for the loss of human immunodeficiency virus type 1 RNA load suppression by zidovudine. Proc. Natl. Acad. Sci. U.S.A. 93, 5501-5506.

Efrros, R. B., Allsopp, R., Chiu, C. P., Hausner, M. A., Hirji, K., WANG, L., et al. (1996). Shortened telomeres in the expanded CD28-CD8 ${ }^{+}$cell subset in HIV disease implicate replicative senescence in HIV pathogenesis. AIDS 10, 0.

Essunger, P. \& Perelson, A. S. (1994). Modeling HIV infection of CD4 ${ }^{+}$T-cell sub-populations. J. theor. Biol. 170, 367-391.

FAUCI, A. S. (1993). Multifactorial nature of human immunodeficiency virus disease: implications for therapy. Science 262, 1011-1018.

Frost, S. D. \& McLean, A. R. (1994). Quasispecies dynamics and the emergence of drug resistance during zidovudine therapy of HIV infection. AIDS 8, 323-332.

Frost, S. D. \& Michie, C. A. (1996). Lymphocyte dynamics, apoptosis and HIV infection. Trends Microbiol. 4, 77-82.

Giacca, M., Zanussi, S., Comar, M., Simonelli, C., Vaccher, E., De Paoli, P. \& Tirelli, U. (1996). Treatment of human immunodeficiency virus infection with hydroxyurea: virologic and clinical evaluation. J. Infect. Dis. 174, 204-209.

GinzburG, L. R. \& AкÇAKaya, H. R. (1992). Consequences of ratio-dependent predation for steady-state properties of ecosystems. Ecology 93, 1536-1543.

Goletti, D., Weissman, D., Jackson, R. W., Graham, N. M., Vlahov, D., KLeIN, R. S., et al. (1996). Effect of mycobacterium tuberculosis on HIV replication. Role of immune activation. $J$. Immunol. 157, 1271-1278.

Goulder, P. J., Phillips, R. E., Colbert, R. A., McAdam, S., OGG, G., NowaK, M. A., et al. (1997). Late escape from an immunodominant cytotoxic T-lymphocyte response associated with progression to AIDS. Nat. Med. 3, 212-217.

Haase, A. T., Henry, K., Zupancic, M., Sedgewick, G., Faust, R. A., Melroe, H., et al. (1996). Quantitative image analysis of HIV-1 infection in lymphoid tissue. Science 274, 985-989.

Hastings, A. \& Powell, T. (1991). Chaos in a three-species food chain. Ecology 72, 896-903.

Ho, D. D., Neumann, A. U., Perelson, A. S., Chen, W., Leonard, J. M. \& Markowitz, M. (1995). Rapid turnover of plasma virions and CD4 lymphocytes in HIV-1 infection. Nature 373, $123-126$.

Huisman, G. \& De Boer, R. J. (1997). A formal derivation of the "Beddington" functional response. J. theor. Biol. 185, $389-400$.

Irvine, D. H. \& Savageau, M. A. (1985a). Network regulation of the immune response: alternative control points for suppressor modulation of effector lymphocytes. J. Immunol. 134, 2100 2116.

IRvine, D. H. \& SavageaU, M. A. (1985b). Network regulation of the immune response: modulation of suppressor lymphocytes by alternative signals including contrasuppression. J. Immunol. 134, 2117-2130.

Klein, M. R., Van BaAlen, C. A., Holwerda, A. M., Kerkhof Garde, S. R., Bende, R. J., Keet, I. P., et al. (1995). Kinetics of Gag-specific cytotoxic $\mathrm{T}$ lymphocyte responses during the clinical course of HIV-1 infection: a longitudinal analysis of rapid progressors and long-term asymptomatics. J. Exp. Med. 181, 1365-1372.

Klenerman, P., Phillips, R. E., Rinaldo, C. R., Wahl, L. M.,
OGG, G., MAY, R. M., et al. (1996). Cytotoxic T lymphocytes and viral turnover in HIV type 1 infection. Proc. Natl. Acad. Sci. U.S.A. 93, 15323-15328.

Kovacs, J. A., Baseler, M., Dewar, R. J., Vogel, S., Davey, JR, R. T., FALloON, J., et al. (1995). Increases in CD4 T lymphocytes with intermittent courses of interleukin-2 in patients with human immunodeficiency virus infection. A preliminary study. N. Engl. J. Med. 332, 567-575.

Larder, B. A., Darby, G. \& Richman, D. D. (1989). HIV with reduced sensitivity to zidovudine (AZT) isolated during prolonged therapy. Science 243, 1731-1734.

Levy, J. A., Mackewicz, C. E. \& Barker, E. (1996). Controlling HIV pathogenesis: the role of the noncytotoxic anti-HIV response of $\mathrm{CD}^{+} \mathrm{T}$ cells. Immunol. Today 17, 217-224.

Lineberger, D. W., Kessler, J. A., Waterbury, J. A., Byrnes, V. W., Massari, F., Staszewski, S. \& Emini, E. A. (1995). Turnover of circulating virion RNA and of cell-associated viral DNA reflects active viral replication in human immunodeficiency virus type 1-infected individuals. J. Virol. 69, $2637-2639$.

LoRi, F., Jessen, H., Foli, A., Lisziewicz, J. \& Matteo, P. S. (1997). Long-term suppression of HIV-1 by hydroxyurea and didanosine. JAMA 277, 1437-1438.

McLean, A. R. \& Kirkwood, T. B. (1990). A model of human immunodeficiency virus infection in T helper cell clones. $J$. theor. Biol. 147, 177-203.

McLean, A. R. \& Nowak, M. A. (1992a). Competition between zidovudine-sensitive and zidovudine-resistant strains of HIV. AIDS 6, 71-79.

MCLean, A. R. \& NowaK, M. A. (1992b). Models of interactions between HIV and other pathogens. J. theor. Biol. 155, 69-86.

Mellors, J. W., Rinaldo, JR, C. R., Gupta, P., White, R. M. Todd, J. A. \& Kingsley, L. A. (1996). Prognosis in HIV-1 infection predicted by the quantity of virus in plasma. Science 272, 1167-1170

Meyand, L., Otto, S. A., Jonker, R. R., Mijnster, M. J., Keet, R. P. \& Miedema, F. (1992). Programmed death of T cells in HIV-1 infection. Science 257, 217-219.

Nowak, M. A., Anderson, R. M., McLean, A. R., Wolfs, T. F., Goudsmit, J. \& MAY, R. M. (1991). Antigenic diversity thresholds and the development of AIDS. Science 254, 963-969.

NowaK, M. A. \& Bangham, C. R. (1996). Population dynamics of immune responses to persistent viruses. Science 272, 74-79.

NowaK, M. A. \& MAY, R. M. (1991). Mathematical biology of HIV infections: antigenic variation and diversity threshold. Math. Biosci. 106, 1-21.

O'Brien, W. A., Grovit-Ferbas, K., Namazi, A., Ovcak-Derzic, S., Wang, H. J., PARK, J., et al. (1995). Human immunodeficiency virus-type 1 replication can be increased in peripheral blood of seropositive patients after influenza vaccination. Blood 86 , 1082-1089.

Pantaleo, G. (1997). How immune-based interventions can change HIV therapy. Nat. Med. 3, 483-486.

Pantaleo, G., Graziosi, C., Demarest, J. F., Butini, L., MonTRONI, M., Fox, C. H., et al. (1993). HIV infection is active and progressive in lymphoid tissue during the clinically latent stage of disease. Nature 362, 355-358.

Perelson, A. S., Essunger, P., Cao, Y., Vesanen, M., Hurley, A., SaKsela, K., et al. (1997). Decay characteristics of HIV-1-infected compartments during combination therapy. Nature 387, $188-191$.

Perelson, A. S., Neumann, A. U., Markowitz, M., Leonard, J. M. \& Ho, D. D. (1996). HIV-1 dynamics in vivo: virion clearance rate, infected cell life-span, and viral generation time. Science 271, 1582-1586

Phillips, A. N. (1996). Reduction of HIV concentration during acute infection: independence from a specific immune response. Science 271, 497-499.

Rinaldo, C., Huang, X. L., Fan, Z. F., Ding, M., Beltz, L., LoGAR, A., et al. (1995). High levels of anti-human immunodeficiency virus type 1 (HIV-1) memory cytotoxic T-lymphocyte activity and low viral load are associated with lack of disease in 
HIV-1-infected long-term nonprogressors. J. Virol. 69, 58385842.

Schellekens, P. T., Tersmette, M., Roos, M. T., Keet, R. P., De Wolf, F., Coutinho, R. A. \& Miedema, F. (1992). Biphasic rate of $\mathrm{CD}^{+}$cell count decline during progression to AIDS correlates with HIV-1 phenotype. AIDS 6, 665-669.

Schenzle, D. (1994). A model for AIDS pathogenesis. Stat. Med. 13, 2067-2079.

Schwarz, A., Offermann, G., Keller, F., Bennhold, I., L'age-Stehr, J., Krause, P. H. \& Mihatsch, M. J. (1993). The effect of cyclosporine on the progression of human immunodeficiency virus type 1 infection transmitted by transplantation-data on four cases and review of the literature. Transplantation 55, 95-103.

SheArer, G. M. \& Clerici, M. (1996). Protective immunity against HIV infection: has nature done the experiment for us? Immunol. Today 17, 21-24.

Simonelli, C., Nasti, G., Vaccher, E., Tirelli, U., Zanussi, S., De Paoli, P., Comar, M. \& Giacca, M. (1996). Hydroxyurea treatment in HIV-infected patients. J. Acquir. Immune Defic. Syndr. Hum. Retrovirol. 13, 462-464.

Stanley, S. K., Ostrowski, M. A., Justement, J. S., Gantt, K., Hedayati, S., Mannix, M., et al. (1996). Effect of immunization with a common recall antigen on viral expression in patients infected with human immunodeficiency virus type 1. N. Engl. J. Med. 334, 1222-1230.

Staprans, S. I., Hamilton, B. L., Follansbee, S. E., Elbeik, T., Barbosa, P., Grant, R. M. \& Feinberg, M. B. (1995). Activation of virus replication after vaccination of HIV-1-infected individuals. J. Exp. Med. 182, 1727-1737.

Stilianakis, N. I., Boucher, C. A., De Jong, M. D., Van Leeuwen, R., Schuurman, R. \& De Boer, R. J. (1997). Clinical data sets of human immunodeficiency virus type 1 reverse transcriptase-resistant mutants explained by a mathematical model. J. Virol. 71, 161-168.

Tersmette, M., Gruters, R. A., De Wolf, F., De Goede, R. E., Lange, J. M., Schellekens, P. T., et al. (1989). Evidence for a role of virulent human immunodeficiency virus (HIV) variants in the pathogenesis of acquired immunodeficiency syndrome: studies on sequential HIV isolates. J. Virol. 63, 2118-2125.

Vila, J., Biron, F., Nugier, F., Vallet, T. \& Peyramond, D. (1996). 1-year follow-up of the use of hydroxycarbamide and didanosine in HIV infection. Lancet 348, 203-204.

Weber, J. \& Galpin, S. (1995). HIV results in the frame. Cyclosporin A. Nature 375, 198.

Wei, X., Ghosh, S. K., Taylor, M. E., Johnson, V. A., Emini, E. A., Deutsch, P., et al. (1995). Viral dynamics in human immunodeficiency virus type 1 infection. Nature 373, 117-122.

Weiss, R. A. (1993). How does HIV cause AIDS? Science 260, $1273-1279$

Weng, N. P., Levine, B. L., June, C. H. \& Hodes, R. J. (1995). Human naive and memory $\mathrm{T}$ lymphocytes differ in telomeric length and replicative potential. Proc. Natl. Acad. Sci. U.S.A. 92, 11091-11094.
Wolinsky, S. M., Korber, B. T., Neumann, A. U., Daniels, M., Kunstman, K. J., Whetsell, A. J., et al. (1996). Adaptive evolution of human immunodeficiency virus-type 1 during the natural course of infection. Science 272, 537-542.

Wolthers, K. C., Bea, G., Wisman, A., Otto, S. A., De Roda Husman, A. M., SCHAFt, N., et al. (1996). T cell telomere length in HIV-1 infection: no evidence for increased $\mathrm{CD}^{+} \mathrm{T}$ cell turnover. Science 274, 1543-1547.

\section{APPENDIX}

We further analyse the self-renewal in the activated $\mathrm{T}$ cell model by making a quasi-steady state assumption for the activated cells, in the absence of the virus. Setting $\mathrm{d} T / \mathrm{d} t=0$ in eqn (5b) we obtain

$$
T=\frac{\alpha_{Q}}{r} Q
$$

which shows that the fraction of activated cells is given by the ratio $\alpha_{Q} / r$. Because $\mathrm{d} T / \mathrm{d} t=0$ we may add eqn (5b) to (5a). By substituting eqn (A.1) into (5a) we obtain for the quiescent cells

$$
\frac{\mathrm{d} Q}{\mathrm{~d} t}=\frac{\alpha Q}{1+\kappa Q}-\delta Q,
$$

where $\alpha \equiv 2 \alpha_{Q}, \delta \equiv \delta_{Q}+\alpha_{Q}$ and $\kappa \equiv\left(1+\alpha_{Q} / r\right) / T_{\max }$. The maximum per capita growth rate is $\alpha-\delta=\alpha_{Q}-\delta_{Q}$, which for our estimate $\delta_{Q}=0.001$ is approximately equal to $\alpha_{Q}$. This model is identical to an earlier model of ours (De Boer \& Perelson, 1994), which was developed from realistic $\mathrm{T}$ cell activation schemes.

The non-trivial equilibrium of eqn (A.2) is at

$$
Q=\frac{\alpha-\delta}{\kappa \delta} .
$$

Because the CD4 cell count is $Q+T=Q\left(1+\alpha_{Q} / r\right)$, we obtain for the uninfected equilibrium $\mathrm{CD} 4$ cell count

$$
\mathrm{CD} 4=\frac{\alpha_{Q}-\delta_{Q}}{\alpha_{Q}+\delta_{Q}} T_{\max },
$$

which always remains below $T_{\max }$. 